\title{
Sugar receptor response of the food-canal taste sensilla in a nectar-feeding swallowtail butterfly, Papilio xuthus
}

\author{
Takashi A. Inoue • Kiyoshi Asaoka • Kazuaki Seta • \\ Daisuke Imaeda $\cdot$ Mamiko Ozaki
}

Received: 7 April 2008 /Revised: 11 November 2008/Accepted: 15 November 2008/Published online: 16 December 2008

(C) The Author(s) 2008. This article is published with open access at Springerlink.com

\begin{abstract}
The feeding behavior in nectar-feeding insects is triggered by a sugar-receptor response in contact chemosensilla. The contact chemosensilla are distributed not only on tarsi and the outside of the proboscis but also on the inside of the food canal in Lepidoptera. Although the chemosensilla inside the food canal are assumed to detect sweet taste during the passage of nectar through the food canal, their electrophysiological function has received little attention. In the nectar-feeding Asian swallowtail butterfly, Papilio xuthus (Lepidoptera: Papilionidae), we found 15- to $30-\mu \mathrm{m}$-long sensilla neatly lined up along the inside galea wall, which forms the food canal in the proboscis. The receptor neurons of these sensilla responded to sucrose. We hypothesized that starch and sucrose compete with each other for a taste receptor site on the sensilla. When we added starch and sucrose to the food-canal sensilla, the
\end{abstract}

T. A. Inoue $\cdot$ K. Asaoka $(\varangle)$

National Institute of Agrobiological Sciences,

Ohwashi 1-2,

Tsukuba, Ibaraki 305-8634, Japan

e-mail: asaoka@affrc.go.jp

K. Seta

Adachi Park of Living Things,

Hokima,

Adachi-ku, Tokyo 121-0064, Japan

D. Imaeda

Department of Applied Biology, Faculty of Textile Science,

Kyoto Institute of Technology,

Matsugasaki,

Sakyo-ku, Kyoto 606-8585, Japan

M. Ozaki

Department of Biology, Faculty of Science, Kobe University,

Nada-ku,

Kobe, Hyogo 657-8501, Japan electrophysiological responses of food-canal sensilla were inhibited in parallel with the food-sucking behavior of the butterflies. These results suggest that the food-canal sensilla are involved in the behavioral control of nectar-sucking in this butterfly species.

Keywords Butterfly · Food-canal sensillum · Taste response $\cdot$ Nectar sucking $\cdot$ Competitive inhibition

\section{Introduction}

Several butterfly species as well as the moth Manduca sexta that feed on flower nectar appear to be guided to foods by visual or olfactory cues (Unno 1980; Kelber and Pfaff 1999; Raguso and Willis 2002; Andersson and Dobson 2003; Koshitaka et al. 2004; Ômura and Honda 2005). Although visual stimulation by flowers or olfactory stimulation by floral scents can induce proboscis extension, it does not lead to nectar-sucking behavior in the absence of taste stimulation. In the nymphalid butterflies Nymphalis antiopa and Vanessa atalanta, Minnich (1921) observed that proboscis extension was induced by the contact of the tarsi with a sugar solution. He proposed that these butterflies have sugar taste receptors on the tarsi of the meso- and metathoracic legs. Morita et al. (1957) recorded the electrophysiological response to sugars from the tarsal sensilla of Vanessa indica. Since that time, many studies have reported the responses of tarsal contact chemosensilla of butterflies to both feeding and oviposition stimuli (Takeda 1961; Fox 1966; Ma and Schoonhoven 1973; Calvert 1974; Ichinose and Honda 1978; Calvert and Hanson 1983; Kusumi and Shibuya 1989; Roessingh et al. 1991; Du et al. 1995; Niki and Kanzaki 1995; Städler et al. 1995; Baur et al. 1998; Tsuchihara et al. 2000). 
In contrast to the confirmed significance of tarsal sensilla in host-plant discrimination by female butterflies, their role in nectar-sucking behavior is not well known. As described in the early studies, not all butterfly species extend their proboscis in response to tarsal stimulation with a sugar solution (Weis 1930; Anderson 1932). Furthermore, in $V$. indica, sugar-sensitive neurons are widely distributed in the tarsal sensilla (Morita et al. 1957; Takeda 1961), whereas only a small proportion of the trichoid sensilla located laterally on the tarsi respond to sugar in Pieris rapae (Städler et al. 1995). Alternatively, many lepidopteran adults have visible styloconic contact chemosensilla on the outside of the proboscis (e.g., Städler et al. 1974; Sellier 1975; Altner and Altner 1986; Paulus and Krenn 1996; Krenn 1998; Krenn et al. 2001; Petr and Stewart 2004; Molleman et al. 2005; Kvello et al. 2006). Three electrophysiological investigations have revealed the presence of sugar-sensitive neurons in the styloconic sensilla and their role in feeding behavior (Städler and Seabrook 1975; Blaney and Simmonds 1988; Ômura et al. 2008). Contact chemosensilla on the inner wall of the galea, which forms the food canal of the proboscis in Lepidoptera, have been described in Pieris brassicae (Eastham and Eassa 1955); two nymphalid butterflies, Vanessa cardui and Aglais io (Sellier 1975; Krenn 1998); and some moths (Faucheux and Chauvin 1980; Walters et al. 1998), but their functions have not been examined. Thus, we morphologically and physiologically characterized the food-canal sensilla in relation to the control of food-sucking behavior in the Asian swallowtail butterfly, Papilio xuthus.

To examine the importance of the food-canal sensilla in food-sucking behavior, we looked at the association between the electrophysiological response from the sensilla and the food-sucking response to various concentrations of sucrose in the absence and presence of starch, a putative taste inhibitor that competes with sucrose for the same receptor site (Hara 1983; Ozaki et al. 1993). If sugar-receptor neurons were to control food-sucking behavior and starch was to compete with sucrose for binding at the sugar receptor site, the electrophysiological and behavioral kinetics would have similar inhibition constants for starch. We measured the inhibition of the electrophysiological and behavioral kinetics by starch and compared the inhibition constants to determine whether sugar-receptor neurons in the food-canal sensilla control food-sucking behavior in the butterfly.

\section{Materials and methods}

\section{Butterflies}

Female Papilio xuthus Linnaeus 1767 were collected from the field (Osaka, Japan) and kept in transparent plastic boxes with leaves of Zanthoxylum ailanthoides. Eggs laid on the leaves were collected. After hatching, the larvae were fed on the leaves of $Z$. ailanthoides until pupation. Four to 7 days after emergence, the adult butterflies were used for our experiments. They were fed on $100 \mathrm{mmol} \mathrm{L}^{-1}$ sucrose until satiation once a day.

Preparation for electron microscopy

To prepare samples for scanning electron microscopy (SEM), forceps were used to divide each proboscis into a pair of galeae. The galeae were cut with scissors at the proximal end, air dried, coated with gold, and then observed under a model JSM-6301F scanning electron microscope (JEOL, Tokyo, Japan).

To prepare samples for transmission electron microscopy (TEM), each galea was cut into 5-mm lengths. The pieces were fixed in $100 \mathrm{mmol} \mathrm{L}^{-1}$ phosphate buffer (pH 7.0) containing 2\% glutaraldehyde and 2\% paraformaldehyde for $1 \mathrm{~h}$ at room temperature, dehydrated through a graded ethanol series, and embedded in Epon 812 (TAAB Laboratories Equipment, Berkshire, UK). Ultra-thin sections (silver-gold interference color) of sensilla were stained with uranyl acetate and lead citrate, followed by observation under a model JEM-1010 transmission electron microscope (JEOL).

\section{Electrophysiological procedure}

A butterfly was placed on its side on a binocular microscope stage and immobilized by fixing its body and wings, which were covered with a thin plastic film, in dental wax. The galeae were separated by forceps and fixed on the stage with adhesive tape to expose the inner wall. An indifferent electrode made of a sharpened tungsten needle was inserted into the head. A glass capillary containing a stimulus solution was used as the recording electrode and was capped on a food-canal sensillum to record the electrical impulses. A platinum wire inserted into the recording glass-capillary electrode was connected to a TastePROBE amplifier (Syntech, Hilversum, The Netherlands). Electrical signals were collected in a computer through an A/D converter (IDAC-2; Syntech) and were analyzed with Autospike software (Syntech).

The electrophysiological responses to sucrose at several different concentrations were also recorded from the sensilla trichodea on the fifth tarsomere of each prothoracic leg. A butterfly lying on its back was fixed under the binocular microscope as before, but the tarsus was attached to expose its ventral surface so that a stimulating/recording electrode could be placed on the sensilla. An indifferent electrode was inserted into the 
tibia. The same apparatus was used to record the electrical signal.

The sucrose solutions were prepared at seven concentrations $\left(5,10,20,40,80,120\right.$, and $\left.160 \mathrm{mmol} \mathrm{L}^{-1}\right)$, and each solution contained $10 \mathrm{mmol} \mathrm{L}^{-1} \mathrm{KCl}$ to enhance conductivity. The highest sucrose concentration $160 \mathrm{mmol}$ $\mathrm{L}^{-1}$ was given because it was enough to provoke maximum response, where the concentration-response curve showed almost plateau. A $1 \%$ starch solution was prepared in heated $10 \mathrm{mmol} \mathrm{L}{ }^{-1} \mathrm{KCl}$ solution and used as a diluent. Beginning at the lowest sucrose concentration, impulses were recorded for $1 \mathrm{~s}$ with and without $1 \%$ starch. To avoid stimulus adaptation, there was a stimulation-free interval of at least 5 min between stimuli.

For the kinetic analysis, the number of impulses $(r)$ generated in $0.2 \mathrm{~s}$ were counted beginning $0.15 \mathrm{~s}$ after the first stimulus. During the first $0.15 \mathrm{~s}$, the impulse frequency transiently increased. This early response, which was investigated by Morita (1969) in blowflies, is the phasic response, an impulse frequency that is not parallel with the receptor potential. Those impulses were not counted in the kinetic analysis. The maximum response, $r_{\mathrm{m}}$, was defined as the number of impulses per $0.2 \mathrm{~s}$ in response to stimulation with $160 \mathrm{mmol} \mathrm{L}^{-1}$ sucrose. The sucrose concentration-response curves were generated by plotting the relative response, $r / r_{\mathrm{m}}$, or the numbers of impulses per $0.2 \mathrm{~s}$ at a given sucrose concentrations $[S]$, normalized to the maximum response. The electrophysiological mid-point constants, defined as the concentrations that produced $50 \%$ of the maximum response in the absence and presence of starch $\left(K_{\mathrm{b}}\right.$ and $\left.K_{\mathrm{b}}{ }^{\prime}\right)$, were experimentally determined by curve fitting to the theoretical equations (Ozaki et al. 1993):

$r / r_{\mathrm{m}}=1 /\left(1+K_{\mathrm{b}} /[S]\right)$

and

$r / r_{\mathrm{m}}=1 /\left(1+K_{b}{ }^{\prime} /[S]\right)$

Morita $(1969,1992)$ proposed a theoretical equation relating the dissociation constant of the sucrose-receptor complex to the electrophysiological mid-point constant. The dissociation constants of the sucrose-receptor complex in the absence and presence of starch $\left(K_{\mathrm{d}}\right.$ and $\left.K_{\mathrm{d}}{ }^{\prime}\right)$ are expressed as: $K_{\mathrm{d}}=K_{\mathrm{b}}(1+s g / G)$ and $K_{\mathrm{d}}{ }^{\prime}=K_{\mathrm{b}}{ }^{\prime}(1+s g / G)$, respectively, where $s$ is the total number of ion channels operated by the sucrose-bound receptor, $g$ is the conductance per channel, and $G$ is the conductance across the receptor membrane in the resting state. In a sugar-receptor neuron with a sucrose receptor that is competitively inhibited by a starch concentration of $[I]$ with the inhibition constant $K_{\mathrm{i}}$, the ratio $K_{\mathrm{d}}{ }^{\prime} / K_{\mathrm{d}}=1+[I] / K_{\mathrm{i}}$, and $K_{\mathrm{b}}{ }^{\prime} / K_{\mathrm{b}}$ can be experimentally determined with starch at $[I]$ as:

$K_{\mathrm{i}}=[I] /\left(K_{\mathrm{d}}{ }^{\prime} / K_{\mathrm{d}}-1\right)=[I] /\left(K_{\mathrm{b}}{ }^{\prime} / K_{\mathrm{b}}-1\right)$.

\section{Behavioral experiments}

The butterflies were fed sucrose solution until the day before the feeding test and then starved for 18 to $24 \mathrm{~h}$ before the test. They were held in place by a paperclip on their wings and satiated with water. We prepared and administered the sucrose solutions from 0 to $250 \mathrm{mmol} \mathrm{L}^{-1}$ (in $10 \mathrm{mmol} \mathrm{L}{ }^{-1} \mathrm{KCl}$ ) in steps of $25 \mathrm{mmol} \mathrm{L}^{-1}$ and with or without $2 \%$ starch. Each solution was drawn into a syringe, and a $5-\mu \mathrm{L}$ droplet was placed on the rolled and coiled proboscis. When a butterfly ingested the solution, the drop on the proboscis decreased in volume. The lowest concentration of sucrose that induced food-sucking behavior during a 2-min observation period was defined as the feeding threshold. In most cases, sucrose concentrations higher than the feeding threshold were ingested within $2 \mathrm{~min}$. When the volume remaining after 2 min was less than $2 \mu \mathrm{L}$, we considered the solution to have been ingested. To examine the contribution of tarsal-receptor neurons to food-sucking behavior, we suspended a $5-\mu \mathrm{L}$ droplet of distilled water on the rolled and coiled proboscis and observed whether the volume of the drop decreased when the tarsi of the prothoracic legs were stimulated with various concentrations of sucrose in the absence or presence of $2 \%$ starch. When more than $4 \mu \mathrm{L}$ remained after $2 \mathrm{~min}$, we considered that the solution had not been ingested.

When the feeding threshold in the absence of starch, $C_{\mathrm{t}}$, increased to $C_{\mathrm{t}}{ }^{\prime}$ in the presence of starch at the concentration [I], then $C_{\mathrm{t}}{ }^{\prime} / C_{\mathrm{t}}=1+[I] / K_{\mathrm{i}}$ (Rang 1971; Hirakawa and Kijima 1980). If the food-sucking behavior is controlled by a sugar-receptor neuron in which starch competes with sucrose for binding at a sugar receptor site, then $K_{\mathrm{i}}$ is calculated with the value of $C_{\mathrm{t}}{ }^{\prime} / C_{\mathrm{t}}$, which is obtained from the behavioral inhibition experiments as:

$K_{\mathrm{i}}=[I] /\left(C_{\mathrm{t}}{ }^{\prime} / C_{\mathrm{t}}-1\right)$.

\section{Results}

Morphology of the food-canal sensilla

Using SEM, we observed the inner galeal wall of $P$. xuthus from one of the paired galeae from each of five males and five females. Many bristle-shaped sensilla were present in 
each galea, along the centerline of its inner wall (Fig. 1a,b). The mean number of sensilla on each galea was similar between males $(39 \pm 3, \mathrm{SD})$ and females $(42 \pm 5)$ (MannWhitney $U$ test, $U=7.5, z=-1.06, p=0.29, n_{\text {male }}=n_{\text {female }}=$ 5 ). Thus, each galea had about 40 sensilla, for a total of about 80 sensilla in the proboscis. Each sensillum had a moderately sharpened tip and a socket at the base and the length varied from 15 to $30 \mu \mathrm{m}$ with a basal diameter of about $3 \mu \mathrm{m}$ (Fig. 1c,d). At the top of the sensillum was a small opening, which is a feature of insect contact chemosensory organs (arrowhead in Fig. 1e). Transverse sections of the cuticular apparatus at 2,14, and $17 \mu \mathrm{m}$ from the top
Fig. 1 Distribution and microstructure of the food-canal sensilla on the inner galeal wall of the proboscis in P. xuthus. a SEM photograph of the inner surface of the right galea. b Schematic of the galea. Asterisks sensilla; bar $=100 \mu \mathrm{m}$. c Enlarged SEM photograph of the inner galeal wall. Arrow sensillum; bar $=10 \mu \mathrm{m}$. d SEM photograph of a sensillum. Arrow socket at the base; bar $=10 \mu \mathrm{m}$. e Enlarged SEM photograph of a sensillum, top view. Arrowhead pore; $b a r=1 \mu \mathrm{m}$. f, g, h TEM photographs of crosssections of a sensillum at 2, 14, and $17 \mu \mathrm{m}$, respectively, from the top of the sensillum. Asterisk in $\mathbf{h}$ indicates the fifth dendritic process, which is probably that of a mechanosensitive neuron. $D$ dendritic process, $I L$ inner lumen, $O L$ outer lumen, $I W$ inner cuticular wall, $O W$ outer cuticular wall. Bars $=1 \mu \mathrm{m}$
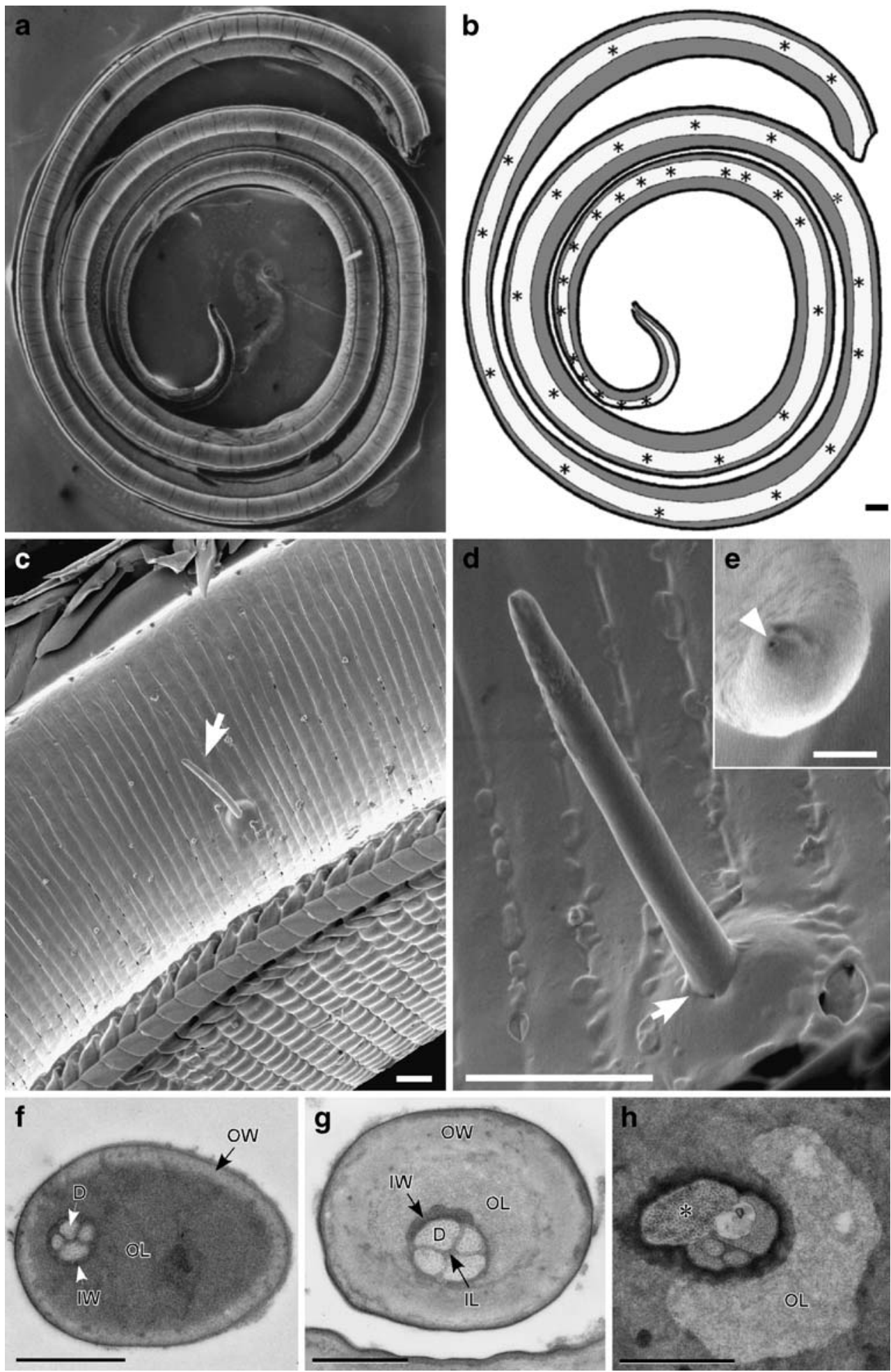


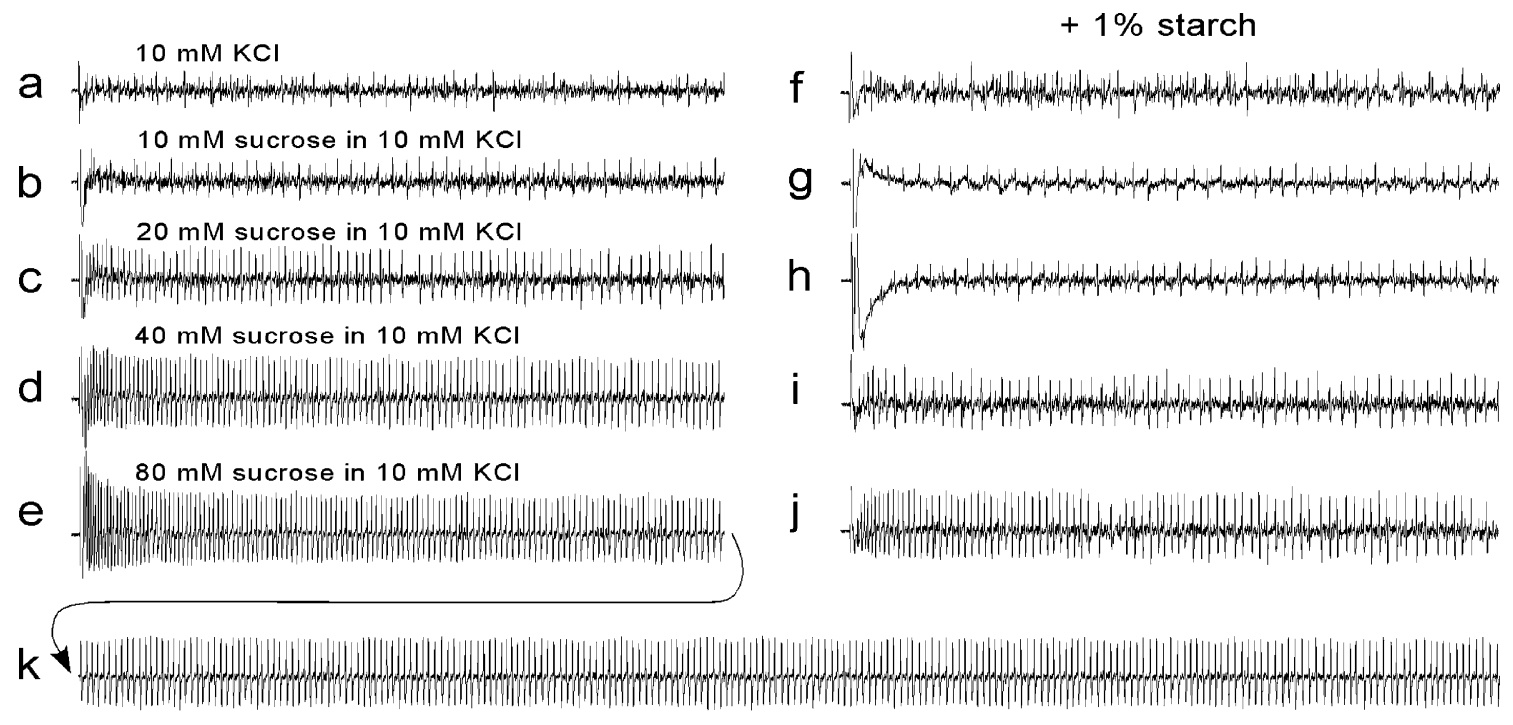

Fig. 2 Representative impulse records from the food-canal sensillum of $P$. xuthus in response to various concentrations of sucrose in the absence (left, a-e) and presence (right, $\mathbf{f}-\mathbf{j})$ of $1 \%$ starch. Each record

of this type of sensillum are shown in Fig. 1f-h. Figure $1 \mathrm{~g}$ is a section at the level of the sensillar socket. The sections of the cuticular apparatus revealed both an inner and outer lumina, which were separated by an inner cuticular wall, through nearly the entire length of the apparatus. The inner lumen contained four dendritic processes along which microtubules are regularly distributed. The processes extended from the four taste-receptor neurons, each of which had a soma at the base of the cuticular apparatus. Near the soma, another dendritic process was visible; this may be derived from the mechanoreceptor neuron (asterisk in Fig. 1h).

Electrophysiological response of the sensillum to sucrose and the inhibitory effect of starch

We recorded the electrophysiological response of the foodcanal sensilla to sucrose at various concentrations. We recorded the sugar-receptor response in 11 of 16 sensilla in two males and two females. The multiple impulses of different amplitudes that were observed may be derived from the salt- or water-receptor neurons (Fig. 2a). However, in response to $10 \mathrm{mmol} \mathrm{L}^{-1} \mathrm{KCl}$ alone, the impulses were hardly discriminable. When the sensillum was stimulated by a sucrose solution, regularly fired impulses of similar amplitude could be discriminated and the impulses from the salt- or water-receptor neurons diminished or disappeared. The number of regular impulses increased in a sucrose concentration-dependent manner, indicating that the impulses originated from the sugar-receptor neuron (Fig. 2b-e). The number of regularly fired impulses from the same sensillum increased in a sucrose concentration- covers $1 \mathrm{~s}$ after the stimulus onset. $\mathbf{k}$ is a continuous trace that follows e for $2.2 \mathrm{~s}$ starting $1 \mathrm{~s}$ after the stimulus onset. Bar=100 ms

dependent manner in response to the stimulus solutions plus $1 \%$ starch. (Fig. $2 \mathrm{~g}-\mathrm{j}$ ); however, the impulse frequency was lower when each response was compared with the same sucrose concentration without starch. When the recording period was extended to $5 \mathrm{~s}$, the response to $80 \mathrm{mmol} \mathrm{L}{ }^{-1}$ sucrose decreased by only $30 \%$. Beginning $1 \mathrm{~s}$ after the onset of stimulation, there was almost a constant impulse frequency (Fig. 2k).

Sensilla responsiveness varied among butterflies; therefore, we acquired concentration-dependent response data from four food-canal sensilla in the same butterfly (Fig. 3). The mean $r_{\mathrm{m}}$ was $28 \pm 4$ impulses per $0.2 \mathrm{~s}(n=4)$. The

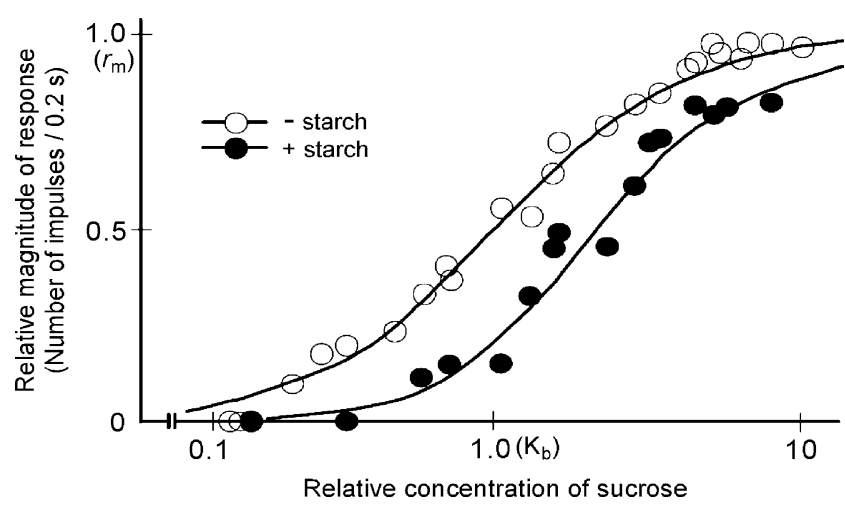

Fig. 3 Curves for sucrose concentration versus electrophysiological response recorded from the food-canal sensilla of $P$. xuthus in the absence and presence of $1 \%$ starch. The magnitudes of the responses of four sensilla from the same butterfly, normalized to the maximum response $\left(r_{\mathrm{m}}\right)$, are plotted against the relative sucrose concentration normalized to the electrophysiological mid-point constants in the absence of $\operatorname{starch}\left(K_{\mathrm{b}}\right)$ 
sucrose concentration-response plot was fitted to Eq. 1 with a mid-point constant, $K_{\mathrm{b}}$, of $26 \pm 5 \mathrm{mmol} \mathrm{L}^{-1}(n=4)$. The relative response, $r / r_{\mathrm{m}}$, was plotted against the relative sucrose concentration to provide a mid-point constant, $K_{\mathrm{b}}$, of unity in the absence of starch (Fig. 3). When 1\% starch was added to the sugar solutions, the sucrose concentration-response curve was fitted to Eq. 2, and the mid-point constant, $K_{\mathrm{b}}{ }^{\prime}$, was $52 \pm 10 \mathrm{mmol} \mathrm{L}^{-1}(n=4)$. Thus, when $1 \%$ starch was added to the sucrose solutions, the curve showed a parallel shift to the right, resulting in a $K_{\mathrm{b}}{ }^{\prime}$ that was twice the $K_{\mathrm{b}}$ in the absence of starch. This parallel shift indicates that starch competitively inhibited the sugar-receptor neuronal response to sucrose. Using Eq. 3, $K_{\mathrm{i}}$ was calculated to be $1.08 \pm 0.25 \%(n=4)$.

We electrophysiologically verified that some trichoid sensilla on the ventral sides of the fifth tarsomeres of the prothoracic legs of both males and females contained sugarreceptor neurons. Figure 4 shows representative impulse

\section{a}

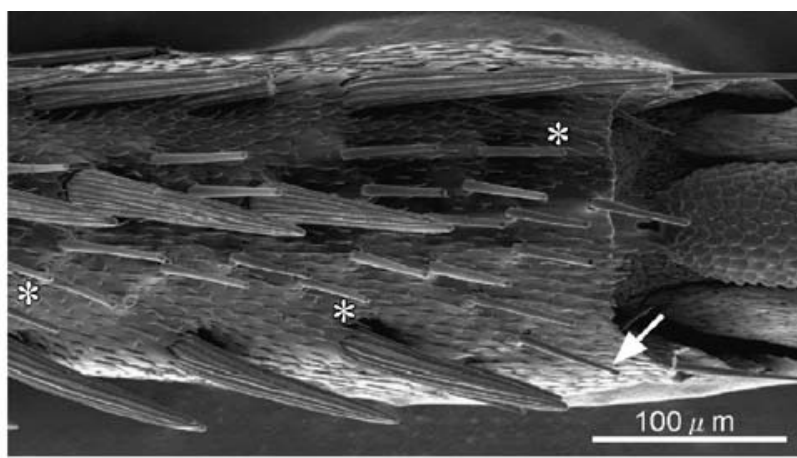

b

$10 \mathrm{mM} \mathrm{KCl}$

\section{$10 \mathrm{mM}$ Sucrose in $10 \mathrm{mM} \mathrm{KCl}$}

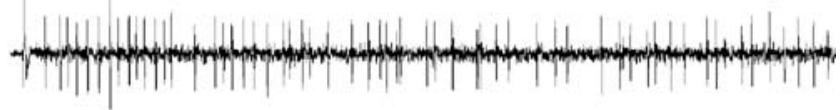

$20 \mathrm{mM}$ Sucrose in $10 \mathrm{mM} \mathrm{KCl}$

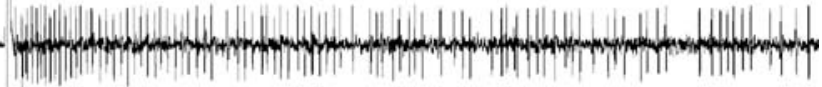

$40 \mathrm{mM}$ Sucrose in $10 \mathrm{mM} \mathrm{KCl}$

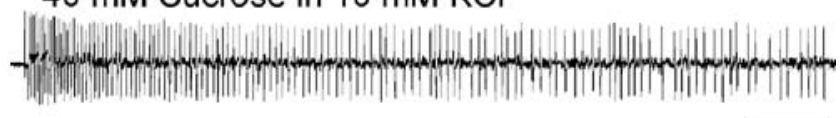

Fig. 4 Electrophysiological response to the sucrose solutions, recorded from the tarsal trichoid sensilla in $P$. xuthus. a SEM photograph showing the ventral side of the fifth tarsomere on the left foreleg of a male. Sucrose responses were recorded from the sensilla (arrow and asterisks). b Representative impulse records from the tarsal sugar-sensitive sensillum (arrow in a). Each record covers $1 \mathrm{~s}$ after the stimulus onset. Bar $=100 \mathrm{~ms}$

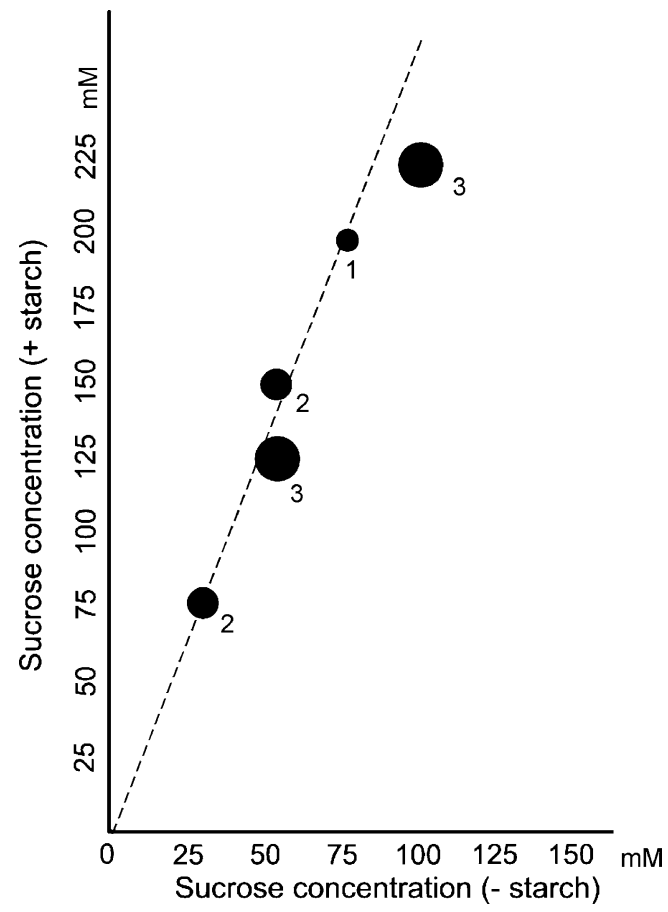

Fig. 5 Food-sucking behavior of $P$. xuthus in response to the sucrose solutions presented as the feeding threshold in the presence of $2 \%$ starch (ordinate) is plotted against that in the absence of starch (abscissa). The diameter of each circle corresponds to the number of butterflies, shown by the adjacent number. The dotted straight line with a slope of $2.6\left(\left(C_{\mathrm{t}}{ }^{\prime} / C_{\mathrm{t}}\right)\right.$ in text $)$ was drawn by the least-squares method

recordings from a sugar-sensitive tarsal sensillum of a male butterfly in response to various concentrations of sucrose in $10 \mathrm{mmol} \mathrm{L}^{-1} \mathrm{KCl}$. The impulse frequency from the sugarreceptor neuron increased as the concentration of sucrose increased.

Behavioral response of butterflies to sucrose and the inhibitory effect of starch

To determine the food-sucking threshold concentration of sucrose, we applied a drop of sucrose at various concentrations to the proboscis and determined the lowest concentration that induced the food-sucking behavior, in the presence and absence of $2 \%$ starch. Individuals showed different threshold values $(n=11$, five males + six females) (Fig. 5). A plot of the threshold concentration of sucrose in the presence of $2 \% \operatorname{starch}\left(C_{\mathrm{t}}{ }^{\prime}\right)$ against that in the absence of starch $\left(C_{\mathrm{t}}\right)$ fit a straight line, as drawn by the leastsquares method, with a slope of $C_{\mathrm{t}}{ }^{\prime} / C_{\mathrm{t}}=2.6$ (Fig. 5). The starch inhibition constant as calculated with Eq. 4 was $K_{\mathrm{i}}=$ $[I] /\left(C_{\mathrm{t}}{ }^{\prime} / C_{\mathrm{t}}-1\right)=1.27 \pm 0.25 \%(n=11)$.

The butterflies did not ingest the water drop when the tarsi were stimulated with sucrose solutions up to $1,000 \mathrm{mmol} \mathrm{L}^{-1}$ ( $n=6$, three males + three females). 


\section{Discussion}

Although the food-canal sensilla of $P$. xuthus appeared to be identical to the previously described sensilla basiconica (Sellier 1975; Faucheux and Chauvin 1980; Krenn 1998; Walters et al. 1998), they are trichoid, as described for $P$. brassicae (Eastham and Eassa 1955). The food-canal sensillum lining the galeal wall housed five sensory neurons; one is probably a mechanoreceptor, and the others are taste receptors. This neural composition is found in the food-canal basiconic sensillum of Choristoneura fumiferana (Walters et al. 1998), the trichoid sensillum on the tarsi of P. brassicae (Ma and Schoonhoven 1973), and many other taste sensilla in various insects (see Zacharuk 1985). As verified in other insects, the four taste-receptor neurons may respond to different fundamental tastes. We defined one of these as the sugar-receptor neuron.

In Heliothis zea (Adler 1989; Lopez et al. 1995) and the nymphalid butterflies $V$. indica and Argyreus hyperbius (Ômura and Honda 2003; Ômura et al. 2008), food-sucking behavior is induced when the proboscis tip is stimulated with a sugar solution. When a sugar solution touches the proboscis tip, it moves up through the food canal by capillary action and stimulates the firing of the sugarreceptor neuron in the sensilla. At this early stage, foodsucking is initiated if the induced receptor response is greater than the behavioral threshold. As the sensilla are stimulated, the taste input is enhanced to maintain sucking. It is therefore likely that the sugar receptors in the foodcanal sensilla are the key neurons driving the food-sucking behavior of $P$. xuthus.

To correlate the electrophysiological response of the sugar-receptor neurons and the food-sucking response of these butterflies, we used starch as a competitive inhibitor of sucrose for the sugar-receptor site, as in the blowfly Phormia regina (Diptera: Calliphoridae) (Hara 1983; Ozaki et al. 1993). Sucrose is a disaccharide having glucopyranose and fructofuranose residues. It is believed that the binding of the starch glucopyranose residue sterically hinders the receptor site, thereby preventing an electrophysiological response. Although the taste information from the sugar-receptor neurons may be transmitted through some intermediate neurons in the brain to stimulate the motor neurons driving food-sucking behavior (Kvello et al. 2006), the competitive inhibition at the receptor site should depress the response of the sugar-receptor neuron and the subsequent feeding response of the butterfly.

As the competitive inhibition for the receptor site is one of the first responses to a sugar stimulus, a kinetic analysis based on this inhibition is valid regardless of the subsequent pathway (Rang 1971; Hirakawa and Kijima 1980). For a competitive inhibitor, the reduction in the probability of activating a receptor in the presence of particular concentrations of a competitive inhibitor and stimulant will be kinetically identical to the reduction in the presence of a decreased concentration of stimulant without the inhibitor. The results of our experiments suggest that when the taste information was translated into taste-receptor neuronal impulses, the subsequent neural mechanisms that induce feeding behavior could not discriminate the nature of stimulus.

In accordance with Rang (1971), if only parallel shifts occur in the electrophysiological or behavioral concentration-response curves in the presence of certain concentrations of a taste inhibitor and the inhibitor only affects the generation of impulses from the receptor neuron, then an "apparent" competitive inhibition constant can be calculated from the appropriate experiments. The finding that the inhibition constants based on our electrophysiological $\left(K_{\mathrm{i}}=\right.$ $1.08 \pm 0.25 \%)$ and behavioral $\left(K_{\mathrm{i}}=1.27 \pm 0.25 \%\right)$ experiments were identical strongly suggests that food-sucking behavior was driven by the experimentally inhibited receptor neuron.

Although some tarsal trichoid sensilla were sucrosesensitive (Fig. 4), the tarsal sensilla did not trigger foodsucking behavior. In P. xuthus, the number and localization of tarsal chemosensilla are sexually dimorphic (Inoue 2006). Certain types of tarsal sensilla that are abundantly distributed in females generate specific impulses in response to host-plant substances (Kusumi and Shibuya 1989; Niki and Kanzaki 1995), suggesting that most of these tarsal sensilla are involved in the search for suitable oviposition sites. As sucrose is not a stimulant for oviposition, the role of sugar-sensitive tarsal sensilla remains unclear. The sugar-sensitive tarsal sensilla may be involved with proboscis extension, which might depend on physiological conditions such as age and starvation, but contact of the food-canal sensilla with distilled water may suppress food-sucking behavior even if tarsal stimulation with sucrose induced proboscis extension. Proboscis extension and food-sucking behavior may be differently regulated, with the sugar-receptor neurons in the food-canal sensilla being more likely to directly control food-sucking behavior than those in the tarsal sensilla.

The sucrose concentration-response curve of the foodcanal sensilla of $P$. xuthus was steeper than that of the sugar-receptor neurons in the largest labellar sensilla of the blowfly P. regina (Hara 1983). This suggests that P. xuthus can sharply discriminate between sucrose concentrations. Considering the energy that butterflies consume in visiting flowers, it would not be economical to ingest sugar at low concentrations. Entomophilous plants prepare a small amount of nectar in each flower, thus forcing nectar-feeding butterflies to visit several flowers in order to acquire sufficient food. This finding emphasizes the importance of 
the relationship between stimulus-concentration dependency and the feeding threshold.

Furthermore, compared with the labellar sugar-receptor neurons of $P$. regina (Ozaki and Amakawa 1992), the sugar-receptor neurons in the food-canal sensilla of $P$. xuthus adapted more slowly to sucrose, as indicated by their long duration of impulse generation (Fig. 2k). This may induce the butterfly to ingest all of the nectar from one flower and then terminate the behavior when the impulse generation ceases. The slow adaptation of the sugarreceptor neurons in the food-canal sensilla is markedly different from the fast adaptation of the sugar-receptor neurons in the styloconic sensilla on the outside of the proboscis in C. fumiferana (Städler and Seabrook 1975), V. indica, and A. hyperbius (Ômura et al. 2008). This suggests different roles for the sensilla located on the inside versus the outside of the proboscis. Further comparative investigations among lepidopteran species are required for an understanding of the physiology and behavioral roles of different types of sensilla.

In almost all lepidopteran species, the food canal of the proboscis, which conducts fluid foods into the cibarial cavity, consists of a pair of elongated maxillary galeae, whereas the food canal is formed from multiple mouthpart elements, such as the labrum, mandibles, maxillae, labium, and hypopharynx, in other orders of fluid-sucking insects (see Backus 1988; Chapman 1998; Krenn et al. 2005). Contact chemosensilla probably taste ingested fluids in the food canal. For example, in some female blood-sucking mosquitoes, including Aedes aegypti (Diptera: Culicidae), apical sensilla at the labial tip of the food canal respond electrophysiologically to adenosine nucleotides and blood plasma components and papilla-like sensilla in the cibarium have the structural features of contact chemosensilla (McIver 1982; Werner-Reiss et al. 1999a, 1999b). The morphology of the contact chemosensilla in the precibarium, which is proximate to the food canal, has been characterized in some hemipteran insects such as aphids and leafhoppers (Backus 1988). The proximal sensilla on the glossae of honeybees, Apis mellifera (Hymenoptera: Apidae), may sense taste when food passes up the food canal (Whitehead and Larsen 1976). However, contact chemosensilla have not been reported to occur on the inside wall of the food canal in these insects, and there have been no electrophysiological studies of the chemosensilla in the cibarial cavity. Thus, our study is the first to demonstrate the function of contact chemosensilla for tasting ingested food in fluid-sucking insects. We propose a functional coupling of the food-canal sensilla and the food-sucking behavior of $P$. xuthus. However, we cannot exclude the possibility that other types of sensilla with sugar-receptor neurons may exist in the cibarium or elsewhere and may control the food-sucking behavior of butterflies.
Acknowledgements This study was supported by a grant from the Promotion of Basic Research Activities for Innovative Biosciences (ProBRAIN) to K.A. and M.O.

Open Access This article is distributed under the terms of the Creative Commons Attribution Noncommercial License which permits any noncommercial use, distribution, and reproduction in any medium, provided the original author(s) and source are credited.

\section{References}

Adler PH (1989) Sugar feeding of the adult corn earworm (Lepidoptera: Noctuidae) in the laboratory. J Econ Entomol 82:1344-1349

Altner H, Altner I (1986) Sensilla with both terminal pore and wall pores on the proboscis of the moth Rhodogastria bubo Walker (Lepidoptera: Arctiidae). Zool Anz 216:129-150

Anderson AL (1932) The sensitivity of the legs of common butterflies to sugars. J Exp Zool 63:235-259

Andersson S, Dobson HEM (2003) Behavioral foraging responses by the butterfly Heliconius melpomene to Lantana camara floral scent. J Chem Ecol 29:2303-2318

Backus EA (1988) Sensory systems and behaviours which mediate hemipteran plant-feeding: a taxonomic overview. J Insect Physiol 34:151-165

Baur R, Haribal M, Renwick JAA, Städler E (1998) Contact chemoreception related to host selection and oviposition behaviour in the monarch butterfly, Danaus plexippus. Physiol Entomol 23:7-19

Blaney WM, Simmonds MSJ (1988) Food selection in adults and larvae of three species of Lepidoptera: a behavioural and electrophysiological study. Entomol Exp Appl 49:111-121

Calvert WH (1974) The external morphology of foretarsal receptors involved with host discrimination by the nymphalid butterfly Chlosyne lacinia. Ann Entomol Soc Am 67:853-856

Calvert WH, Hanson FE (1983) The role of sensory structures and preoviposition behavior in oviposition by the patch butterfly, Chlosyne lacinia. Entomol Exp Appl 33:179-187

Chapman RF (1998) The insects: structure and function, 4th edn. Cambridge University Press, Cambridge

Du Y-J, van Loon JJA, Renwick JAA (1995) Contact chemoreception of oviposition-stimulating glucosinolates and oviposition-deterrent cardenolide in two subspecies of Pieris napi. Physiol Entomol 20:164-174

Eastham LES, Eassa YEE (1955) The feeding mechanism of the butterfly Pieris brassicae L. Phil Trans R Soc Lond B 230 (659): $1-43$

Faucheux MJ, Chauvin G (1980) Les pièces buccales des adultes de cinq Lépidoptères tinéides kératophages communs dans l'ouest de la France. III-Les récepteurs sensoriels des maxilles. Bull Soc Sci Nat Ouest France, nouvelle série 2:16-25

Fox RM (1966) Forelegs of butterflies 1. J Res Lepid 5:1-12

Hara M (1983) Competition of polysaccharides with sugar for the pyranose and the furanose sites in the labellar sugar receptor cell of the blowfly Phormia regina. J Insect Physiol 29:113-118

Hirakawa Y, Kijima H (1980) Behavioral analysis of glutathione receptor of Hydra. 1. Mouth-opening threshold, inhibition constant and their temperature-dependence. J Comp Physiol 137:73-81

Ichinose T, Honda H (1978) Ovipositional behavior of Papilio protenor demetrius Cramer and the factors involved in its host plants. Appl Entomol Zool 13:103-114 
Inoue TA (2006) Morphology of foretarsal ventral surfaces of Japanese Papilio butterflies and relations between these morphology, phylogeny and hostplant preferring hierarchy. Zool Sci 23:169-189

Kelber A, Pfaff M (1999) True colour vision in the orchard butterfly, Papilio aegeus. Naturwissenschaften 86:221-224

Koshitaka H, Kinoshita M, Arikawa K (2004) Action spectrum of foraging behavior of the Japanese yellow swallowtail butterfly, Papilio xuthus. Acta Biol Hung 55:71-79

Krenn HW (1998) Proboscis sensilla in Vanessa cardui (Nymphalidae, Lepidoptera): functional morphology and significance in flowerprobing. Zoomorphology 118:23-30

Krenn HW, Zulka KP, Gatschnegg T (2001) Proboscis morphology and food preference in nymphalid butterflies (Lepidoptera: Nymphalidae). J Zool Lond 254:17-26

Krenn HW, Plant JD, Szucsich NU (2005) Mouthparts of flowervisiting insects. Arthropod Struct Dev 34:1-40

Kusumi K, Shibuya T (1989) Response of the tarsal contact chemoreceptor of the Citrus feeding swallowtail butterfly releasing the oviposition behavior. Zool Sci 6(suppl.):1076

Kvello P, Almaas TJ, Mustaparta H (2006) A confined taste area in a lepidopteran brain. Arthropod Struct Dev 35:35-45

Lopez JD Jr, Lingren PD, Bull DL (1995) Proboscis extension response of adult Helicoverpa zea (Lepidoptera: Noctuidae) to dry sugars. J Econ Entomol 88:1271-1278

Ma WC, Schoonhoven LM (1973) Tarsal contact chemosensory hairs of the large white butterfly Pieris brassicae and their possible role in oviposition behaviour. Entomol Exp Appl $16: 343-357$

McIver SB (1982) Sensilla of mosquitoes (Diptera: Culicidae). J Med Entomol 19:489-535

Minnich DE (1921) An experimental study of the tarsal chemoreceptors of the nymphalid butterflies. J Exp Zool 33:173-203

Molleman F, Krenn HW, van Alphen ME, Brakefield PM, Devries PJ, Zwaan BJ (2005) Food intake of fruit-feeding butterflies: evidence for adaptive variation in proboscis morphology. Biol $\mathrm{J}$ Linn Soc 86:333-343

Morita H (1969) Electric signals of taste receptor activity. In: Pfaffmann C (ed) Olfaction and taste III. Rockefeller University Press, New York, pp 370-381

Morita H (1992) Transduction process and impulse initiation in insect contact chemoreceptor. Zool Sci 9:1-16

Morita H, Doira S, Takeda K, Kuwabara M (1957) Electrical response of contact chemoreceptor on tarsus of the butterfly Vanessa indica. Mem Fac Kyushu Univ Ser E 2:119-139

Niki S, Kanzaki R (1995) Responses of tarsal contact chemoreceptors to oviposition stimulants in swallowtail butterfly, Papilio xuthus. Zool Sci 12(suppl.): 101

Ômura H, Honda K (2003) Feeding responses of adult butterflies, Nymphalis xanthomelas, Kaniska canace and Vanessa indica, to components in tree sap and rotting fruits: synergistic effects of ethanol and acetic acid on sugar responsiveness. J Insect Physiol 49:1031-1038

Ômura H, Honda K (2005) Priority of color over scent during flower visitation by adult Vanessa indica butterflies. Oecologia 142: $588-596$

Ômura H, Honda K, Asaoka K, Inoue TA (2008) Tolerance to fermentation products in sugar reception: gustatory adaptation of adult butterfly proboscis for feeding on rotting foods. J Comp Physiol A 194:545-555
Ozaki M, Amakawa T (1992) Adaptation-promoting effect of $\mathrm{IP}_{3}, \mathrm{Ca}^{2+}$, and phorbol ester on the sugar taste receptor cell of the blowfly, Phormia regina. J Gen Physiol 100:867-879

Ozaki M, Amakawa T, Ozaki K, Tokunaga F (1993) Two types of sugar-binding protein in the labellum of the fly. J Gen Physiol 102:201-216

Paulus HF, Krenn HW (1996) Vergleichende Morphologie des Schmetterlingsrüssels und seiner Sensillen - ein Beitrag zur phylogenetischen Systematik der Papilionoidea (Insecta, Lepidoptera). J Zoo Syst Evol Research 34:203-216

Petr D, Stewart KW (2004) Comparative morphology of sensilla styloconica on the proboscis of North American Nymphalidae and other selected taxa (Lepidoptera): systematic and ecological considerations. Trans Am Entomol Soc 130:293-409

Raguso RA, Willis MA (2002) Synergy between visual and olfactory cues in nectar feeding by naïve hawkmoths, Manduca sexta. Anim Behav 64:685-695

Rang HP (1971) Drug receptors and their function. Nature 231:91-96

Roessingh P, Städler E, Schöni R, Feeny P (1991) Tarsal contact chemoreceptors of the black swallowtail butterfly Papilio polyxenes: responses to phytochemicals from host- and non-host plants. Physiol Entomol 16:485-495

Sellier R (1975) Étude ultrastructurale en microscopie électronique par balayage des organs sensoriels de la trompe des lepidoptères rhopalocères. Alexanor 9:9-5

Städler E, Seabrook WD (1975) Chemoreceptors on the proboscis of the female eastern spruce budworm: electrophysiological study. Entomol Exp Appl 18:153-160

Städler E, Städler-Steinbrüchel M, Seabrook WD (1974) Chemoreceptors on the proboscis of the female eastern spruce budworm. I Morphological and histological study. Mitt Schweiz Entomol Gesellsch 47:63-68

Städler E, Renwick JAA, Radke CD, Sachdev-Gupta K (1995) Tarsal contact chemoreceptor response to glucosinolates and cardenolides mediating oviposition in Pieris rapae. Physiol Entomol 20:175-187

Takeda K (1961) The nature of impulses of single tarsal chemoreceptors in the butterfly Vanessa indica. J Cell Comp Physiol 58:233-245

Tsuchihara K, Ueno K, Yamanaka A, Isono K, Endo K, Nishida R (2000) A putative binding protein for lipophilic substances related to butterfly oviposition. FEBS Lett 478:299-303

Unno K (1980) World of butterflies. Kyouritsu, Tokyo

Walters BD, Albert PJ, Zacharuk RY (1998) Morphology and ultrastructure of sensilla on the proboscis of the adult spruce budworm, Choristoneura fumiferana (Clem.) (Lepidoptera: Tortricidae). Can J Zool 76:466-479

Weis I (1930) Versuche über die Geschmacksrezeption durch die Tarsen des Admirals, Pyrameis atalanta L. Z vergl Physiol 12:206-248

Werner-Reiss U, Galm R, Crnjar R, Liscia A (1999a) Sensitivity of the mosquito Aedes aegypti (Culicidae) labral apical chemoreceptors to blood plasma components. J Insect Physiol 45:485-491

Werner-Reiss U, Galm R, Crnjar R, Liscia A (1999b) Sensitivity of the mosquito Aedes aegypti (Culicidae) labral apical chemoreceptors to phagostimulants. J Insect Physiol 45:629-636

Whitehead AT, Larsen JR (1976) Ultrastructure of the contact chemoreceptors of Apis mellifera L. (Hymenoptera: Apidae). Int J Insect Morphol Embryol 5:301-315

Zacharuk RY (1985) Antennae and sensilla. In: Kerkut GA, Gibert LI (eds) Comprehensive insect physiology, biochemistry and pharmacology, vol. vol. 6. Pergamon, New York, pp 1-69 